University of Nebraska - Lincoln

DigitalCommons@University of Nebraska - Lincoln

\title{
Predicting the stability of low volume road embankments in contingency areas
}

\author{
E. Alex Baylot \\ Geotechnical and Structures Laboratory, alex.baylot@usace.army.mil \\ George L. Mason \\ Geotechnical and Structures Laboratory \\ John G. Green \\ Geotechnical and Structures Laboratory \\ Ernest S. Berney IV \\ Geotechnical and Structures Laboratory
}

Follow this and additional works at: https://digitalcommons.unl.edu/usarmyresearch

Baylot, E. Alex; Mason, George L.; Green, John G.; and Berney, Ernest S. IV, "Predicting the stability of low volume road embankments in contingency areas" (2012). US Army Research. 180.

https://digitalcommons.unl.edu/usarmyresearch/180

This Article is brought to you for free and open access by the U.S. Department of Defense at DigitalCommons@University of Nebraska - Lincoln. It has been accepted for inclusion in US Army Research by an authorized administrator of DigitalCommons@University of Nebraska - Lincoln. 


\title{
Predicting the stability of low volume road embankments in contingency areas
}

\author{
E. Alex Baylot*, George L. Mason, John G. Green, Ernest S. Berney IV \\ US Army Engineer Research and Development Center, Geotechnical and Structures Laboratory, 3909 Halls Ferry Road, Vicksburg, MS 39180, USA
}

Received 6 May 2011; received in revised form 21 August 2011; accepted 13 January 2012

Available online 11 February 2012

\begin{abstract}
The US Army often operates heavy vehicles in rural areas, operating on low-volume roads having limited load carrying capacity. Many of these roads, such as the ones on the outskirts of Baghdad, have been raised to prevent flooding from nearby canals or irrigated fields. Sections of the roads have collapsed under the weight of armored vehicles, resulting in injuries and even fatalities. For the selected area studied, $2 \frac{1}{2} \%$ of the low-volume road sections were determined to be high risk given typical wheel loads of heavy vehicles for soil strength conditions modeled as low. The goal of the research was to develop a method for rapidly evaluating the stability of a road based on soil conditions, wheel load, and the dimensions of a vehicle. A model for road stability was developed to assist in performing analysis of the canal roads outside of Baghdad. This analysis was then used to create maps and charts characterizing road stability to assist the drivers. The procedure described in this paper can be used to evaluate elevated roads in other parts of the world.
\end{abstract}

Published by Elsevier Ltd. on behalf of ISTVS.

Keywords: Low volume road; Embankment; Traffic; Heavy vehicles; Trafficability; Soil strength; Stability

\section{Introduction}

The US Army recently deployed a heavier wheeled troop transport family of vehicles, entitled the Mine Resistant Ambush Protected (MRAP) and the Up-Armored High Mobility Multipurpose Wheeled Vehicle (UA-HMMWV), to help ensure safety of the troops. However, in many contingency areas around the world, indigenous roads are constructed of poor quality materials and will not support the weights of these vehicles. In certain areas, such as in Iraq, the roads on which these vehicles operate are actually the tops of raised embankments constructed to prevent flooding from nearby fields and canals. These embankments are constructed at slope angles exceeding safe design limits as presented in DeLeys and Parada [1] and Viner [2],

\footnotetext{
Permission to publish was granted by Director, Geotechnical \& Structures Laboratory.

* Corresponding author. Tel.: +1 601634 3474; fax: +1 6016343068.

E-mail address: alex.baylot@usace.army.mil (E. Alex Baylot).
}

creating slope stability issues along narrow shoulders. They are affected by rains that reduce the soil strength and, thus, increase the chance of failure of the roadbed. Since the introduction of these MRAP vehicles, numerous rollovers have occurred when drivers negotiate the narrow roads that exist around the irrigation canals in Iraq. Over 30\% of these rollovers - some with fatalities and significant injuries - were recorded as a direct result of ledge, slope, or ground collapse. In this study, we present a method of rapidly evaluating the road stability based on soil strength, soil type, and road dimensions combined with information related to the dimensions and weight of the vehicle.

The evaluation method relies on three key components, (a) development of a slope stability tool to predict a Factor-of-Safety (FS) against failure, (b) determination of soil input parameters to guide the slope stability calculations in a software tool, and (c) a software tool to allow visualization of the road network and the geometries of embankment slopes. The slope stability tool was based on a simple wedge method to predict where critical sections of 


\section{Nomenclature}

FS Factor-of-Safety

$P_{\text {vehicle }}$ static load of wheel $(\mathrm{N})$

$w \quad$ distance from edge to wheel center, offset (m)

$\beta \quad$ embankment angle (radians)

$\alpha \quad$ angle formed by failure plain of wedge (radians)

$n \quad$ number of wedge slices evaluated

$T_{s} \quad$ passive resistance of wedge slice (N)

$N_{s} \quad$ passive force on wedge slice (N)

$S \quad$ whole number from 1 to 20

$h_{s} \quad$ distance from top of bank to bottom of wedge (m)

$F_{s} \quad$ weight of soil wedge $(\mathrm{N})$ $\gamma \quad$ bulk density of soil $\left(\mathrm{kg} / \mathrm{m}^{3}\right)$

$d_{\text {wheel }} \quad$ diameter of tire/wheel (m)

$L_{w} \quad$ length along each wedge slice (m)

$N_{x s} \quad$ passive resistance on wedge slice, $\mathrm{x}$ vector component $(\mathrm{N})$

$N_{y s} \quad$ passive resistance on wedge slice, y vector component $(\mathrm{N})$

c soil cohesion $\left(\mathrm{kN} / \mathrm{m}^{2}\right)$

$\varphi \quad$ internal angle of friction (radians)

CI cone index (psi)

$\mathrm{RCI}$ rating cone index (psi) road would be prone to failure when traversed by a given vehicle. Soil parameters were obtained from trafficability cone data [3] that were correlated to strength parameters supported by soil samples taken from the embankments of available field data. Terrain feature extraction was based on a geo-spatial information system application whereby aerial road network surveys can be displayed and embankment geometries can be extracted from Light Detection and Ranging (LIDAR) remotely sensed data. The combined knowledge of vehicle loads, embankment geometry and soil strength allows identification of restricted areas of trafficking throughout the road network, increasing logistic movement, and decreasing risk of injury.

\section{Algorithm development}

An algorithm was developed to identify the critical sections of roads that would be prone to failure when traversed by a heavy vehicle. The slope stability tool developed was based on a simple wedge method. More complex slope stability tools were determined unnecessary given the limited ability to obtain detailed soil properties, which included gradation, moisture content, density, and

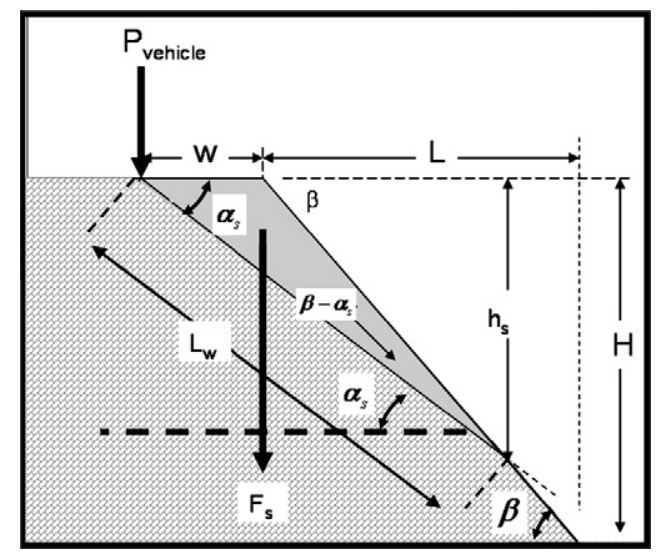

Fig. 1. Illustration of failure-plane analysis of canal road berm. strength parameters. The model is designed to predict the FS against slope failure when the embankment is traversed by a vehicle with a given wheel load and a specific offset from the edge of the embankment.

As shown in Fig. 1, the failure plane of the road is defined by the static load of the wheel, $P_{\text {vehicle }}$, at a distance of $w$ from the edge of the roadbed. The wedge method was used to define the FS as given in Lambe and Whitman [4]. The embankment angle, $\beta$ (radians) was provided from field measurements or data obtained from LIDAR imagery. The angle, $\alpha$, as shown in Fig. 1, was further divided into a discrete number, $n$, of slices within the wedge (emanating from the point at $P_{\text {vehicle }}$ ) to compute the passive resistance, $T_{s}$, and passive force, $N_{s}$, for each slice. For this problem series, $n$, was set equal to 20 , which was adequate for determining the minimum FS. The angle of the soil wedge, $\alpha$, was divided into $n$ sections using Eq. (1). The value of $S$ was iterated as a whole number from 1 to 20 and thus serves to provide $\alpha$ as a fraction of $\beta$.

$\alpha_{s}=\frac{S}{n} * \beta$

The height of the wedge was computed from the estimated distance of the center of the wheel from the side of the road $(w)$, the embankment angle $(\beta)$, and the angle of the wedge slice $(\alpha)$ (Eq. (2)).

$h_{s}=\frac{w * \tan (\beta) * \tan \left(\alpha_{s}\right)}{\tan (\beta)-\tan \left(\alpha_{s}\right)}$

The weight of the soil acting on the wedge slice $\left(F_{s}\right)$ was computed using Eq. (3), based on measured or inferred bulk density of the soil $(\gamma)$. The sum of $F_{s}$ and the load of the wheel on the road $\left(P_{\text {wheel }}\right)$ was used to compute the force $N_{s}$ acting on the embankment wedge (Eq. (4)). Wheel load was actually distributed over an area that falls on both sides of the representative point load. The contact area was approximated as a rectangle for a radial tire. The dimensions would be equal to the tire tread width by that same tire tread width multiplied to a range of numbers (0.6: 1.10) that would depend on the tire deflection and 
other factors. However, this is the initial contact area. Once the failure begins, the entire diameter of the tire $\left(d_{\text {wheel }}\right)$ may come into play and serves to approximate the depth of the wedge slice parallel to the direction of travel.

$F_{s}=\frac{1}{2} \cdot w \cdot \sin \left(\alpha_{s}\right) \cdot L_{w} \cdot d_{\text {wheel }} \cdot \gamma$

$N_{s}=F_{s}+P_{\text {wheel }}$

For each wedge slice, the force vector components were computed $\left(N_{x s}\right)$ and $\left(N_{y s}\right)$ for each wedge slice $(s)$, Eqs. (5) and (6), respectively.

$N_{x s}=N_{s} \cdot \sin \left(\alpha_{s}\right)$

$N_{y s}=N_{s} \cdot \cos \left(\alpha_{s}\right)$

The length along each wedge slice $\left(L_{w}\right)$, as illustrated in Fig. 1, was computed using Eq. (7). The distance $\left(h_{s}\right)$ decreases as the angle $\left(\alpha_{s}\right)$ decreases. The total resistive force $\left(T_{s}\right)$ for each wedge slice was computed using Eq. $(8)$, soil cohesion $(c)$ and internal angle of friction $(\varphi)$.

$L_{w=} \frac{h_{s}}{\sin (\alpha)}$

$T_{s}=N_{y} \cdot \tan (\varphi)+c \cdot L_{w} \cdot d_{\text {wheel }}$

With the offset $(w)$ held constant using Eq. (9), the total resistive force $\left(T_{s}\right)$ was divided by the force acting to dislodge the embankment $\left(N_{x}\right)$. The minimum value ratio computed by iterating through the 20 slices of the wedge is reported as the defining FS.

For a homogeneous distribution of a low-plasticity clay soil (CL), Fig. 2 is an illustration of these computations, given a realistic wheel load of $44.8 \mathrm{kN}$, a bank slope of 0.59 radians, a soil density of $1535 \mathrm{~kg} / \mathrm{m}^{3}$, a soil cohesion of $15.0 \mathrm{kN} / \mathrm{m}^{2}$, a wheel/wedge depth of $1 \mathrm{~m}$ and an internal angle of friction of 0.28 radians. Analyses showed that failure will occur when the offset is $0.3 \mathrm{~m}(1 \mathrm{ft})$ and $\alpha$ is 0.32 radians.

$F S_{s}=\frac{T_{s}}{N_{x}}$

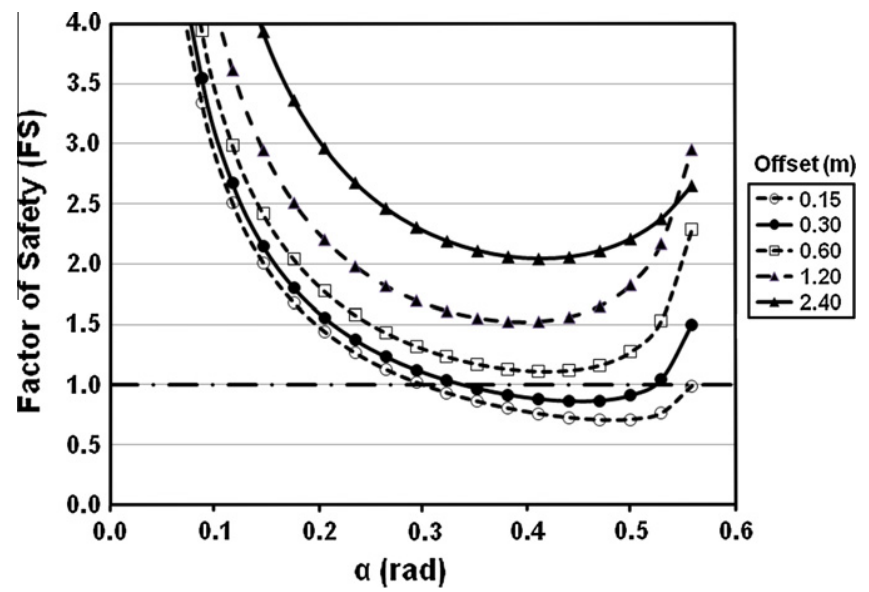

Fig. 2. FS for a low-plasticity clay (CL) wedge computed from an example loading at five offsets on as many as 20 wedge slices.
To test this approximation, comparisons with the slope stability model UTEXAS4 as described by Wright [5] were performed. The comparisons showed a suitable approximation of this nonlinear effect.

\section{Input parameter development}

Constitutive input parameters for the model include soil bulk density, soil internal angle of friction and soil cohesion. Additionally, dimensional inputs of the embankment, vehicle wheel force and width measured at tire centers are required. Because of a limited ability to obtain detailed soil properties from laboratory evaluation and the complex moisture regime within elevated embankments, the internal angle of friction and cohesion are based upon the total stress response and not the effective stress response.

\subsection{Soil properties}

The internal angle of friction and cohesion of the soil are required but extremely difficult to obtain in direct field measurements. However, since field expedient methods are the expectation, translation procedures for measuring soil properties are required. The properties of the internal angle of friction and cohesion are two of the defining properties of a soil's resistance to shear. Thus, the bearing strength of a soil is a strong indicator of its internal angle of friction and cohesion. Since there are a number of field expedient means to measure soil strength, this is a natural alternative to measuring internal angle of friction and cohesion directly.

One field expedient method for measuring soil strength is the cone index $(\mathrm{CI})$ given as pounds-per-square inch (psi) as an average from the surface to a depth of $0.15 \mathrm{~m}$ (6 in.) [3]. The CI collection technique provides a rapid method to quickly collect soil strength data in the field. Additionally, the $\mathrm{CI}$ is normalized to a rating cone index (RCI) by multiplying it by the remolding index given for a particular Unified Soil Classification System (USCS) soil type [3]. An existing specialized computer model, Strength Estimates from Cone Index Testing (SECIT) was used to convert RCI to cohesion and the internal angle of friction for a particular USCS soil type. Further reading on this mathematical model is found in Farr et al. [6], and an earlier version appears in Meier and Baladi [7].

The canal roads' design for this study is based on a raised roadbed built from cultivated fields. The canal roads, which typically lack a paved surface, appear to be loam or clay soil. Due to the heavy loads of the vehicles stated herein, the canal roads appear to fail due to shearing of the roadbed edge, resulting in the vehicles' subsequently overturning.

To support the calibration of soil strength, soils data were collected in theater along a few canal roads. Data for seven sites were collected and are shown in Table 1. Soil CI strengths on-road ranged from 153 to 750 . Lower soil CI strengths, ranging from CI values of 102 to 505, were observed on the shoulders of canal roads. 
Table 1

Summary of data collected from canal roads in Iraq.

\begin{tabular}{|c|c|c|c|c|c|c|}
\hline Sample & Road width (m) & Bank height $(\mathrm{m})$ & Road CI (psi) & Shoulder width $(\mathrm{m})$ & Bank slope $(\%)$ & Shoulder CI (psi) \\
\hline 1 & 4.242 & 0.914 & 726 & 0.914 & 27 & 230 \\
\hline 2 & 3.505 & 2.133 & 351 & N/A & $200^{*}$ & 248 \\
\hline 3 & 8.229 & 3.048 & 440 & 2.133 & 75 & 117 \\
\hline 4 & 3.962 & 0.914 & 750 & 3.048 & 18 & 102 \\
\hline 5 & 4.572 & 6.400 & 153 & 2.743 & 25 & 183 \\
\hline 6 & 3.962 & 0.610 & 636 & 1.118 & 100 & 505 \\
\hline 7 & 7.620 & 2.133 & 681 & 1.829 & 450 & 501 \\
\hline
\end{tabular}

* Percent slope for Sample 2 estimated.

Table 2

Soil properties as estimated by SECIT for an RCI value of 200 .

\begin{tabular}{llll}
\hline USCS type & $\begin{array}{l}\text { Internal angle of } \\
\text { friction (rad) }\end{array}$ & $\begin{array}{l}\text { Cohesion } \\
\left(\mathrm{kN} / \mathrm{m}^{2}\right)\end{array}$ & $\begin{array}{l}\text { Density } \\
\left(\mathrm{kg} / \mathrm{m}^{3}\right)\end{array}$ \\
\hline Clayey sand (SC) & 0.46 & 12.5 & 1444 \\
$\begin{array}{c}\text { Clay-low plasticity } \\
\quad(\mathrm{CL})\end{array}$ & 0.28 & 15.0 & 1535 \\
$\begin{array}{c}\text { Clay-high } \\
\text { plasticity (CH) }\end{array}$ & 0.27 & 24.6 & 1369 \\
$\begin{array}{c}\text { Silt-high plasticity } \\
(\mathrm{MH})\end{array}$ & 0.42 & 8.5 & 1289 \\
\hline
\end{tabular}

Taking a mid-range value point of $250 \mathrm{CI}$ and normalizing it to an RCI value of 200 (assuming a remold index of 0.8 ), the SECIT model returned the estimated values of internal angle of friction, cohesion, and bulk density for four soil types as shown in Table 2. ${ }^{1}$ The embankments were assumed to have a homogeneous soil and moisture distribution, even though the waterline may have existed $1-2 \mathrm{~m}$ below the surface of the road. If water saturation near the surface occurs, cohesive soil strength will decrease from diffusion.

To compare the SECIT model and assumptions with the field collected data, a series of undisturbed soils sampled with a drive cylinder were taken at one particular location outside Baghdad. This embankment consisted of highly plastic clay with some silts that classified as a $\mathrm{CH}$ material. Laboratory testing showed higher bulk densities than assumed, varying between 1470 and $1762 \mathrm{~kg} / \mathrm{m}^{3}$. Comparing the estimated value given for $\mathrm{CH}$ in Table 2 with this range is acceptable as the soil samples collected were not a pure $\mathrm{CH}$. Confined undrained triaxial tests conducted at three different confining pressures (69-, 275- and 827$\mathrm{kPa}$ ) with the soils' original in situ moisture content revealed a total stress internal angle of friction of 0.51 radians $(29 \mathrm{deg})$ and cohesion of $39.4 \mathrm{kN} / \mathrm{m}^{2}(5.7 \mathrm{psi})$. These values were taken from the trend-line given the data sets of the four collection sites shown in Fig. 3.

Furthering the comparison between the SECIT model and the laboratory results, Table 3 yields the SECIT model estimates based on an RCI of 360 whereby the bulk density

\footnotetext{
${ }^{1}$ Values were interpolated from the predicted values provided in Tables 12 and 13 of Farr et al. [6].
}

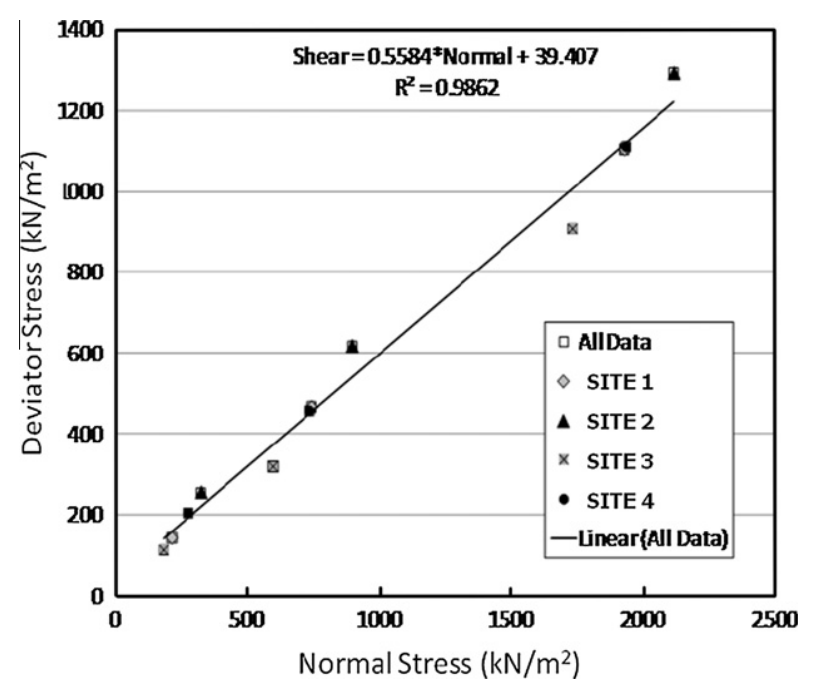

Fig. 3. Stress path plot for embankment $\mathrm{CH}$ soils collected for study.

Table 3

Soil properties as estimated by SECIT for an RCI value of 360 .

\begin{tabular}{llll}
\hline USCS type & $\begin{array}{l}\text { Internal angle } \\
\text { of friction }(\mathrm{rad})\end{array}$ & $\begin{array}{l}\text { Cohesion } \\
\left(\mathrm{kN} / \mathrm{m}^{2}\right)\end{array}$ & $\begin{array}{l}\text { Density } \\
\left(\mathrm{kg} / \mathrm{m}^{3}\right)\end{array}$ \\
\hline Clayey sand (SC) & 0.51 & 24.0 & 1610 \\
Clay-low plasticity (CL) & 0.35 & 24.0 & 1640 \\
Clay-high plasticity (CH) & 0.31 & 44.8 & 1470 \\
Silt-high plasticity (MH) & 0.44 & 18.4 & 1335 \\
\hline
\end{tabular}

of $1470 \mathrm{~kg} / \mathrm{m}^{3}$ as estimated by SECIT and the lowest measured value are common to both.

When set at this higher density, the SECIT model predicted a slightly higher value of cohesion and a higher internal angle of friction than before, bringing it closer to the laboratory results. In comparison, the differences between the SECIT estimates and the measured values are acceptable for estimation, considering that the actual soils taken in the field contained some silt, which does exhibit a higher internal angle of friction as evident in Table 3 . Given that the slope stability model is much more sensitive to the internal angle of friction than to the cohesion, the model results will be conservative. Fig. 4 provides the graphs of a $\mathrm{CH}$ at an RCI of 360. Compare this to the CL at an RCI of 200 in Fig. 1. 


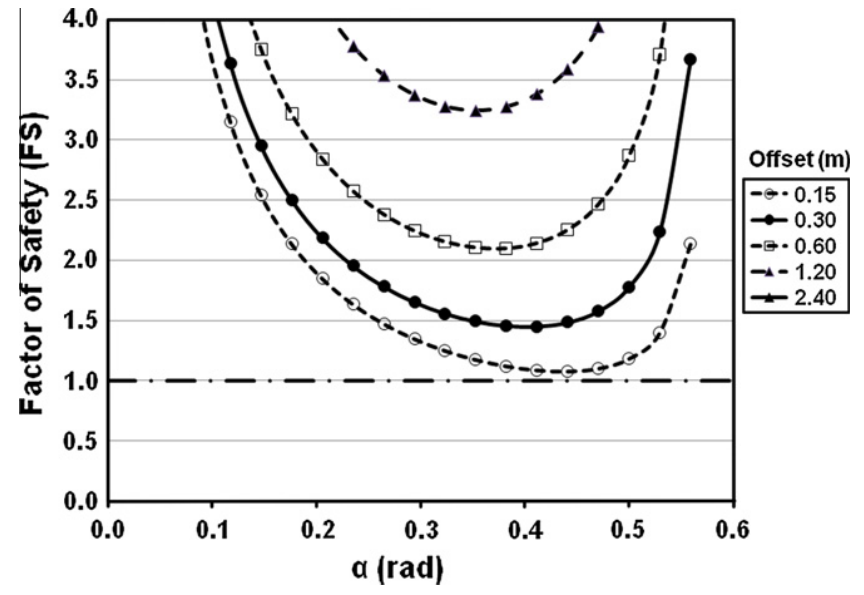

Fig. 4. FS for a high-plasticity clay $(\mathrm{CH})$ wedge computed from an example loading of $44.8 \mathrm{kN}$ at five offsets on as many as 20 wedge slices and an RCI of 360 .

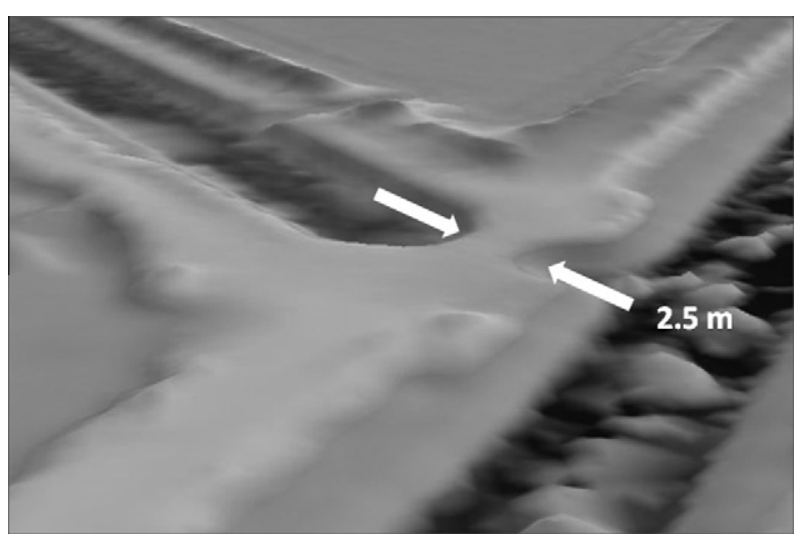

Fig. 5. An example of canal road with grayed changes for elevation (white highest, black lowest).

\subsection{Embankment geometry}

The algorithm presented requires the bank slope and the width of the roadbed. These required variables were collected from remote sensing data and are summarized in Table 1. The slope along the side of the canal roads was computed from 1-m LIDAR data (Fig. 5), and the width of the canal roads was measured from $0.1-\mathrm{m}$ resolution geo-referenced imagery. Critical points of concern were found at sites where roads narrowed due to culvert emplacement. These narrow passages are not much wider than the heavy vehicles under study. Thus, for traversing roads as studied herein, the vehicle will have to travel close to the edge of the roadbed. The resolution of the LIDAR and imagery established a solid basis for assessing height, width and slope of embankments as shown in Fig. 5.

\section{Analysis}

The analysis of the road embankments was conducted in two parts. Point analysis was used for selected cross-sec-
Table 4

Critical vehicle data.

\begin{tabular}{llllll}
\hline Vehicle & $\begin{array}{l}\text { Number } \\
\text { of axles }\end{array}$ & $\begin{array}{l}\text { Axle length } \\
\text { between tire } \\
\text { centers }(\mathrm{m})\end{array}$ & $\begin{array}{l}\text { Tire } \\
\text { diameter } \\
(\mathrm{m})\end{array}$ & $\begin{array}{l}\text { GVW } \\
(\mathrm{kN})\end{array}$ & $\begin{array}{l}\text { Maximum } \\
\text { single wheel } \\
\text { load }(\mathrm{kN})\end{array}$ \\
\hline UA-HMMWV & 2 & 2.9 & 0.9 & 66.7 & 9.0 \\
MRAP 1 & 2 & 2.6 & 1.2 & 133.5 & 35.2 \\
MRAP 2 & 2 & 3.4 & 1.1 & 166.8 & 49.3 \\
MRAP 3 & 2 & 3.5 & 1.2 & 193.5 & 56.1 \\
MRAP 4 & 3 & 3.0 & 1.2 & 214.4 & 37.1 \\
MRAP 5 & 3 & 3.3 & 1.2 & 234.5 & 44.8 \\
\hline
\end{tabular}

${ }^{*}$ Useful as an approximation of soil wedge depth.

Table 5

Slope stability for 44.8-kN wheel load (MRAP 5).

\begin{tabular}{llll}
\hline Offset, $w(\mathrm{~m})$ & Bank Slope, $\beta$ (radians) $(\%)$ & FS $^{\mathrm{a}}$ & Risk \\
\hline 0.15 & $0.32(33)$ & 1.51 & Moderate \\
0.30 & $0.32(33)$ & 1.92 & Moderate \\
0.60 & $0.32(33)$ & 2.62 & Low \\
1.20 & $0.32(33)$ & 3.88 & Low \\
2.40 & $0.32(33)$ & 5.95 & Low \\
0.15 & $0.59(67)$ & 0.81 & High \\
0.30 & $0.59(67)$ & 1.01 & Moderate \\
0.60 & $0.59(67)$ & 1.39 & Moderate \\
1.20 & $0.59(67)$ & 2.04 & Low \\
2.40 & $0.59(67)$ & 2.97 & Low \\
0.15 & $0.79(100)$ & 0.56 & High \\
0.30 & $0.79(100)$ & 0.73 & High \\
0.60 & $0.79(100)$ & 1.01 & Moderate \\
1.20 & $0.79(100)$ & 1.47 & Moderate \\
2.40 & $0.79(100)$ & 2.08 & Low \\
\hline
\end{tabular}

${ }^{\text {a }}$ Factor-of-Safety computed using soil density of $1369 \mathrm{~kg} / \mathrm{m}^{3}$, soil cohesion of $24.6 \mathrm{kN} / \mathrm{m}^{2}$, internal angle of friction $0.27 \mathrm{rad}(\mathrm{CH})$, tire diameter/wedge depth $1 \mathrm{~m}$.

tions, and area analysis was used for the entire road network.

\subsection{Point analysis}

The wheeled vehicles in the study range from the lightest wheel load, the UA-HMMWV at $9.0 \mathrm{kN}$, to the heaviest tactical MRAP vehicle wheel load, at $56.1 \mathrm{kN}$. As the MRAP is a family of vehicles with various shapes and dimensions, five representative configurations were chosen and are labeled MRAP 1-5 for brevity. The vehicle widths are considered wide enough that failure of the road edge is due to an isolated wheel load. The axle lengths for the vehicles in Table 4 are large enough to suggest that immediate failure of the soil surface is due to isolated wheel loads and not to the cumulative effects of the vehicle. Using a tire diameter of $1 \mathrm{~m}$ is a good simplified common value for this list of vehicles and conservative for the depth of the wedge slice.

Table 5 illustrates the failure plane analysis by iterating between shoulder offsets, $w$, of 0.15 and $2.4 \mathrm{~m}$ and bank slopes, $\beta$, between 0.32 and 0.79 radians $(33 \%$ and $100 \%$, respectively). The values presented in Table 2 for $\mathrm{CH}$ are 
used as input into the soil stability model as presented. The sum of the wheel load and the weight of the underlying soil is compared to the available strength of the soil supporting the wheel load in terms of the cohesive force and internal angle of friction. For our purposes in this study, the point-of-failure or road failure is reached when the wheel loading exceeds the supporting load characterized by the soil wedge. This occurs when the FS is less than 1.0 as modeled by Eq. (9). Driver caution is suggested between the FS values of 1.0 and 2.0. Low risk is associated with values higher than 2.0.

\subsection{Area analysis}

A rural area-of-interest was selected outside the Baghdad area. The entire rural area contained $845 \mathrm{~km}$ of roads, which were comprised of $320 \mathrm{~km}$ of vehicle trails, $342 \mathrm{~km}$ of secondary roads, $178 \mathrm{~km}$ of primary roads, and a 5$\mathrm{km}$ section of highway. Secondary roads and vehicle trails along the canals were of particular interest to this study because they were raised above the ground level by $2-4$ $\mathrm{m}$ and had no improved road surface.

As previously stated, over $30 \%$ of the rollover mishaps that occurred with heavy vehicles were due to ground surface failures. The described algorithm was developed as a computer model and imbedded into the North Atlantic Treaty Organization Reference Mobility Model (NRMM) as described in Ahlvin and Haley [8]. The model was used to determine whether the road could support the vehicle traffic based on wheel loading, vehicle width, road soil strength, and road geometry.

The terrain attributes derived from remotely sensed imagery and elevation data were used to drive the NRMM embankment model and predict which road segments would fail given particular vehicle loadings and soil condi-

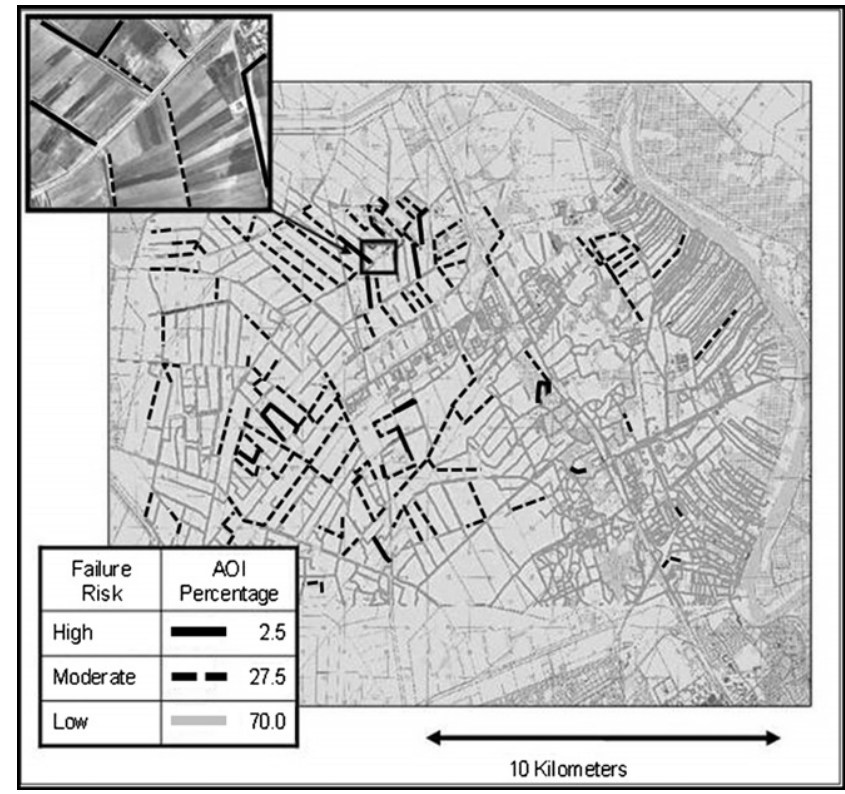

Fig. 7. Mapping of road restrictions for MRAP 5 with a $44.8-\mathrm{kN}$ wheel load.

tions. Fig. 6 is an aggregation of these data sources, and the NRMM predicted results are shown in the lower right quadrant.

Fig. 7 represents the entire area results of MRAP 5 when the soil strength is set between 100 and $200 \mathrm{RCI}$ for a CL soil type. This map shows the road stability analysis, where $2.5 \%$ of roads were of high risk (severely restricted), $27.5 \%$ were of moderate risk (restricted), and $70 \%$ were of low risk (unrestricted). Soil strengths between 125 and $150 \mathrm{CI}$ appear to be the minimum threshold for safe operation of vehicles along the canal roads. Below this RCI level, the terrain accessibility is severely restricted.

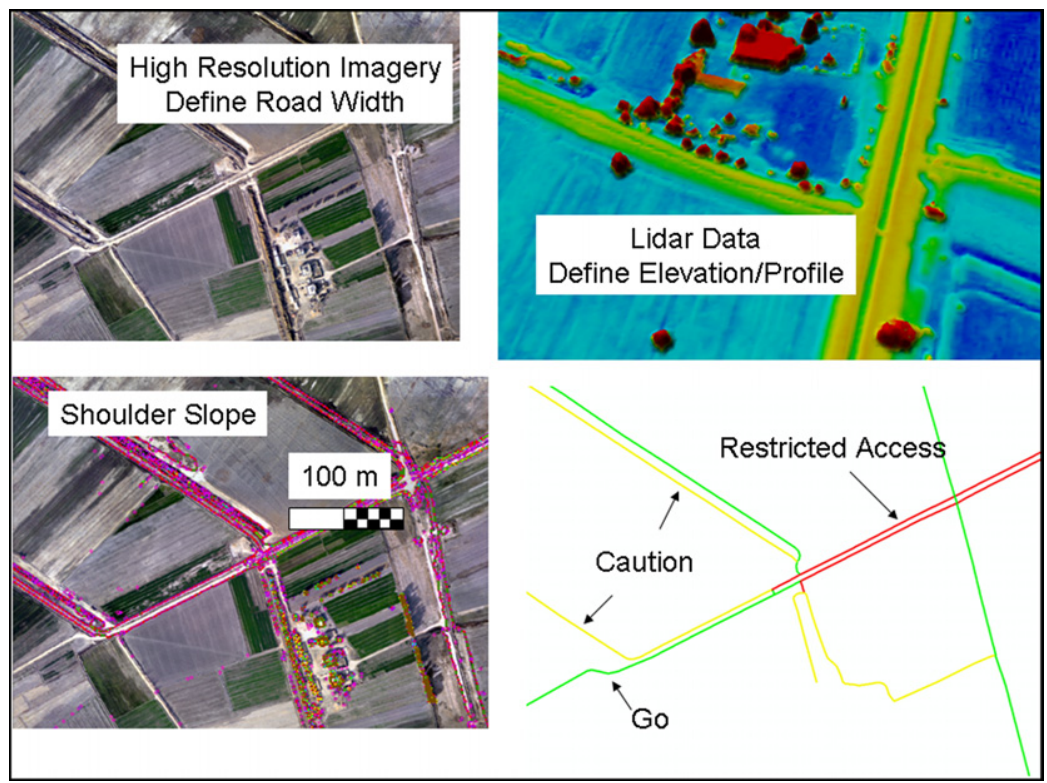

Fig. 6. Data attribution for canal road model. 


\begin{tabular}{|c|c|c|c|c|c|c|c|c|}
\hline \multirow{4}{*}{\multicolumn{6}{|c|}{$\begin{array}{l}\text { Low Volume Road with Clay Base and Sub-base } \\
\text { Rut Depth }=12.7 \mathrm{~cm} ; \mathrm{RCl}=90 \\
\text { Wet Soft Strength Clay }(\mathrm{CH}) \\
\text { Wheel Load } 44.8 \mathrm{kN}\end{array}$}} & \multicolumn{3}{|c|}{ Risk Level } \\
\hline & & & & & & \multirow{3}{*}{$\begin{array}{l}\text { Low } \\
\text { Med } \\
\text { High } \\
\end{array}$} & \multirow{3}{*}{\multicolumn{2}{|c|}{$\begin{array}{l}\mathrm{SF} \geq 2 \\
1<\mathrm{SF}<2 \\
\mathrm{SF} \leq 1\end{array}$}} \\
\hline & & & & & & & & \\
\hline & & & & & & & & \\
\hline \multirow{3}{*}{ Bank Slope } & \multicolumn{8}{|c|}{ Distance From Road Edge $(\mathrm{cm})$} \\
\hline & 0 & 30 & 60 & 90 & 120 & 150 & 180 & $200 \geq$ \\
\hline & \multicolumn{8}{|c|}{ Factor of Safety (FS) (Embankment Strength/Load) } \\
\hline $0 \%$ & $\infty$ & $\infty$ & $\infty$ & $\infty$ & $\infty$ & $\infty$ & $\infty$ & $\infty$ \\
\hline $10 \%$ & 2.9 & 4.4 & 5.5 & 6.6 & 7.6 & 8.4 & 9.3 & 9.9 \\
\hline $20 \%$ & 1.5 & 2.2 & 2.8 & 3.3 & 3.8 & 4.2 & 4.6 & 4.9 \\
\hline $30 \%$ & 0.9 & 1.3 & 1.7 & 2.0 & 2.3 & 2.8 & 3.1 & 3.3 \\
\hline $40 \%$ & 0.7 & 1.2 & 1.4 & 1.7 & 1.9 & 2.1 & 2.3 & 2.4 \\
\hline $50 \%$ & 0.6 & 0.9 & 1.1 & 1.4 & 1.6 & 1.7 & 1.9 & 2.0 \\
\hline $60 \%$ & 0.5 & 0.8 & 1.0 & 1.2 & 1.3 & 1.5 & 1.6 & 1.7 \\
\hline $70 \%$ & 0.4 & 0.7 & 0.9 & 1.0 & 1.2 & 1.3 & 1.4 & 1.4 \\
\hline $80 \%$ & 0.4 & 0.6 & 0.8 & 0.9 & 1.0 & 1.1 & 1.2 & 1.3 \\
\hline $90 \%$ & 0.3 & 0.5 & 0.7 & 0.8 & 0.9 & 1.0 & 1.1 & 1.2 \\
\hline $100 \%$ & 0.3 & 0.5 & 0.6 & 0.8 & 0.9 & 0.9 & 1.0 & 1.1 \\
\hline $200 \%$ & 0.2 & 0.3 & 0.4 & 0.5 & 0.6 & 0.6 & 0.6 & 0.7 \\
\hline
\end{tabular}

Fig. 8. Notional medium tactical vehicle operation guide for canal roads.

Another approach developed through the analysis was to provide a chart that graphically stated the conditions at which safe vehicle operation would be at risk. The chart could be used as a guide so drivers could rapidly determine whether their vehicle should operate on the approaching road segment. Fig. 8 is representative of such a chart for the MRAP 5. The conditions presented were configured for a $\mathrm{CH}$ soil with an RCI of 90 on the road embankment edge and a wheel load of $44.8 \mathrm{kN}$. This is a wet condition with the vehicle producing a $12.7-\mathrm{cm}$ rut. The red, yellow, and green zones indicate the operational risk as a function of bank slope and offset distance from the wheel center and embankment edge. The values of the FS are given in each cell, although the drivers need to understand only the significance of the color schemes.

\section{Summary and conclusions}

Roads in rural areas are often ill-suited for heavily armored wheeled or tracked vehicles. Failures of the slopes along these roads create hazardous conditions for vehicles. Using the dimensions of the road and the wheel loads of the vehicle, an FS can be assigned to the road. For roads in the rural areas of Iraq, data suggest that when soil strengths measured in the top $15 \mathrm{~cm}$ are less than 150 RCI on fine-grained, unimproved raised canal roads, vehicles with individual wheel loads of $44.8 \mathrm{kN}$ or greater will experience severe restrictions to movement.

Although most of the road segments may be characterized as low risk, as evidenced by the analysis, one has to take into account that this is a road system. Since it is expected that multiple vehicles will eventually travel over all segments within the road system, system failure is immi- nent because at least one vehicle will eventually cross over a high risk segment. When guidance is provided either on a map or in a chart, the high risk areas can be avoided, thereby reducing accidents significantly. The presented algorithm is not limited to the particular area studied herein and could be used to define stability of low-volume canal roads in other areas of the world.

Further research is recommended in studying the effects of tire footprint and the effects of dynamic forces on the stability of the slope. These effects were outside the scope of this study, however it would likely prove useful to understand the sensitivity of slope stability to tire footprint and a dynamic load versus a static load.

\section{Acknowledgements}

Permission to publish was granted by Director, Geotechnical \& Structures Laboratory. The study was conducted in support of the US Army Infantry Center and the Army Capabilities Integration Center, US Army Training and Doctrine Command. Messrs Tom Stafford and William McLaughlin, Combat Developments Specialists, US Army Infantry Center, were the technical points of contact. Data defining the number and types of mishaps of the MRAP in theater were obtained from Mr. Alfred Rice, working with the Pentagon's Deployments and Operations Task Force under the auspices of the Defense Safety Oversight Council. Initial findings were presented at the Joint 9th Asia-Pacific ISTVS Conference and Annual Meeting of Japanese Society for Terramechanics [9].

\section{References}

[1] DeLeys NJ, Parada LO. Rollover potential of vehicles on embankments, sideslopes and other roadside features. Federal Highway Administration Technical Report FHWA/RD-86/164. McLean, VA: U.S. Dept. of Transportation; 1986.

[2] Viner JG. Rollover on sideslopes and ditches. Transport Res Board Acc Anal Prevent 1995;27(4):483-91.

[3] ISTVS Standards Committee. International society for terrain-vehicle systems standards. J Terramech 1977;14(3):153-82.

[4] Lambe WT, Whitman TW. Soil mechanics. Hoboken, NJ: John Wiley \& Sons, Inc; 1969.

[5] Wright S. UTEXAS4: a computer program for slope stability calculations. Austin, TX: Shinoak Software; 1999.

[6] Farr JV, Rabalais CP, Underwood RB, Ahlvin RB. Mobility and plowing capabilities of the combat mobility vehicle. TR GL-91-6, Vicksburg, MS: U.S. Army Engineer Research and Development Center; 1991

[7] Meier RW, Baladi GY. Cone-index-based estimates of soil strength: theory and user's guide for computer code CIBESS. SL-88-11, Vicksburg, MS: U.S. Army Engineer Research and Development Center; 1988

[8] Ahlvin RB, Haley PW. NATO reference mobility model. Edition II, NRMM user's guide. GL-92-19. Vicksburg, MS: U.S. Army Engineer Research and Engineering Center; 1992.

[9] Mason GL, Baylot EA, Green JG. Predicting the stability of raised low volume roads in contingency areas. Proceedings of the Joint 9th AsiaPacific ISTVS conference and annual meeting of Japanese Society for terramechanics, Sapporo, Japan; 2010. 